\title{
Laparoscopic Heller's Myotomy with Dor Wrap versus Pneumatic Dilatation in Treatment of Achalasia: A Prospective Randomized Study
}

\author{
Gamal Fawzy, ${ }^{I}$ MD; Moheb Shoraby, ${ }^{1}$ MD; Hany Haroun Kaisar, ${ }^{2}$ MD
}

1) Department of General Surgery, Ain Shams University, Cairo, Egypt.

2) Department of Internal Medicine, Ain Shams University, Cairo, Egypt.

Background: There are currently two different treatment modalities available for treatment of achalsia; pneumatic dilation (PD) and Heller myotomy (HM). Both of them are focused on decreasing the LES resting pressure thereby allowing the distal esophagus to empty with the aid of gravity. Ideally, the choice between the 2 treatment options should be based upon prospective, randomized and comparative studies. Studies comparing pneumatic dilatation with rigiflex balloon and laparoscopic Heller myotomy have recently been reported. This study aims to compare the results of pneumatic dilatation versus laparoscopic Heller's myotomy combined with Dor fundoplication in cases of achalasia of the cardia to consider which group of patients should be subjected to either methods for better management.

Methods: This study is a prospective randomized clinical trial conducted in Ain Shams University Hospitals during the period from June 2012 till October 2014. Thirty patients who were diagnosed as having achalsia were randomized into 2 groups: group A included 15 patients who underwent pneumatic dilatation and group B included 15 patients who underwent laparoscopic Heller's myotomy.

Results: The mean operative time was significantly longer in Heller's myotomy group [99 (80-120min)] than pneumatic dilatation group [46.6(40-60min)] $(P<0.001)$. The mean hospital stay was significantly longer in the HM group 2.1 days than the PD group 1.1 day $(P<$ 0.001). There was no need for conversion to open Heller's in the HM. There was no significant difference in the incidence of intraoperative complications between both groups. There was a statistically significant lower symptom scoring in the HM group than PD group $(P<0.001)$. Postoperative complications in the form of reflux symptoms and recurrence of achalasia symptoms were significantly lower in the HM group than the PD group $(P<0.001)$.

Conclusion: Laparoscopic cardiomyotomy was found to be superior to an endoscopic balloon dilatation strategy in the treatment of achalasia when studied during the first 12 month after treatment with special care must be taken in the future studies to laparoscopic myotomy alone as it is thought to be the best way for the management of achalasia in the future.

Key words: Achalasia of cardia, laparoscopic Heller's myotomy, pneumatic dilatation

\section{Introduction:}

Achalasia is a primary motility disorder of the esophagus, occurring in approximately 1 per 100.000 population per year. In the normal esophagus, peristaltic waves follow each swallow, while in case of achalasia a neuromuscular defect produces a marked decrease or absence of esophageal body peristalsis. $^{1}$

In achalasia, the lower esophageal sphincter is hypertonic producing resting pressures above normal and relaxing incompletely after swallowing. This produces a functional obstruction resulting in dilatation and elongation of the body of the esophagus with a rapid narrowing at the cardia. ${ }^{2}$ 
The reason for this disorder is the degeneration of microscopic ganglion cells in Auerbach myenteric plexus. The clinical diagnosis is always symptoms-based: dysphagia, retrosternal pain, regurgitation of stagnant food, weight loss. Esophageal manometric study is the gold standard for establishing the diagnosis of achalasia. Althoughelevated LES pressures $(>35 \mathrm{~mm} \mathrm{Hg})$ may be evident, the most classic and specific manometric finding is incomplete sphincter relaxation, which occurs in more than $80 \%$ of the patients. Barium esophagogram reveals a dilated esophagus with a classic "bird's beak" of the GE junction, with atonic and dilated esophageal body. ${ }^{2}$

The treatment of achalasia is palliative since the underlying motility disorder cannot be corrected. Relief of dysphagia and the obstructing high-pressure of the lower esophageal sphincter with the prevention of esophageal reflux constitutes the goal of therapy. $^{2}$

The treatment options of achalsia include: drug therapy, injection of botulinum toxin, pneumatic dilatation and Heller's myotomy. Among these the last two are the commonest methods used for untreated achalasia, however none of these methods reverses the underlying neuropathology of achalasia. ${ }^{3}$

Pneumatic dilation is the most effective non surgical therapy for achalasia. The reported incidence of perforation of the esophagus ranges from $0 \%$ to $15 \%$ either infra or supradiaphragmatic. ${ }^{4}$

Laparoscopic myotomy of the LES is by far the best treatment modality with satisfactory long-term results. Intraoperative endoscopy during videoscopic Heller myotomy guides the extent and adequacy of myotomy. Although postoperative complications are rare (less than $4 \%$ ) the most seen ones are: mucosal leakage, incomplete myotomy and gastro esophageal reflux if antireflux measures were omitted. 5

This study aims to compare the results of pneumatic dilatation versus laparoscopic Heller's myotomy combined with Dor fundoplication in cases of achalasia of the cardia.

\section{Patient and methods:}

During the period from June 2012 till October 2014, thirty patients with achalasia at Ain Shams University Hospitals (recruited from the internal medicine endoscopy unit) were randomly categorized dividing the patients alternatively into 2 groups: Group A: included 15 patients who were planned to undergo pneumatic dilatation and group B: included 15 patients who were planned to be operated on for by laparoscopic Heller's myotomy with Dor wrap.

All the patients were subjected to:

- Full clinical assessment including history and physical examination including achalasia severity scoring system described by Valiukenas and his colleagues. ${ }^{5}$

- Routine preoperative laboratory investigations.

- Abdominal sonography.

- UGI endoscopy with or without esophageal biopsy.

- Barium study

- Manometric studies.

We followed the following achalasia severity scoring system described by Valiukenas et al: 5

Procedure:

\section{A- Dilatation:}

Group (A): 15 patients who underwent pneumatic dilatation using $40 \mathrm{~mm}$ microvasive balloon under pressure of $15 \mathrm{psi}$ maintained for $60 \mathrm{sec}$.

The objective of this therapy was to produce a complete disruption of the musculature of the LES, in essence rendering it incompetent, resulting in relief of distal esophageal obstruction and symptomatic improvement. It was of course mandatory to achieve an effective muscle disruption yet refrain from perforating the esophagus.

All the 15 patients received pre-medication in the form of IV Deprivan.

With this technique, a balloon was placed across the LES under direct endoscopic visualization and fluoroscopic control. The balloon was inflated for $1 \mathrm{~min}$ to a pressure of 15 psi. 


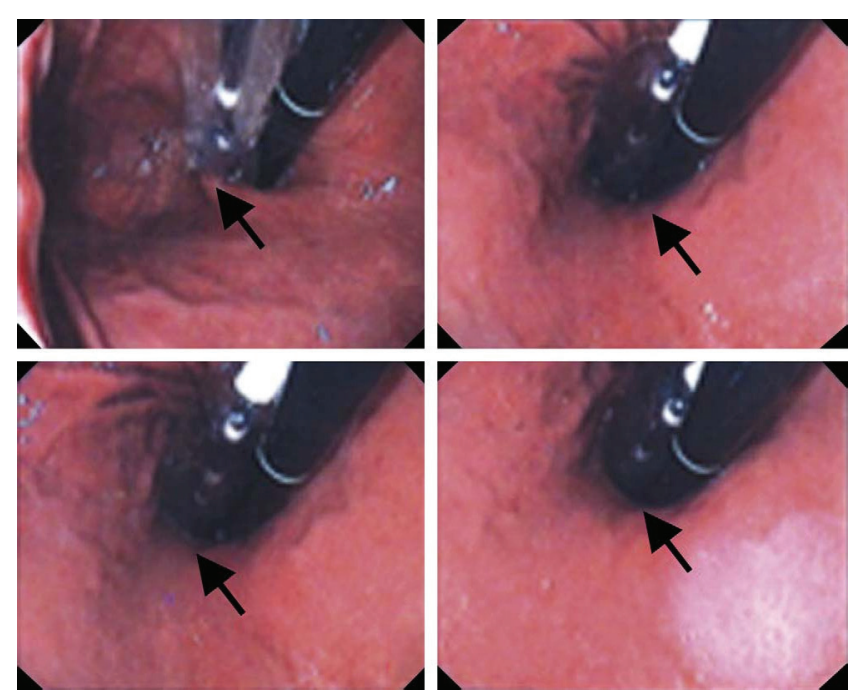

Figure (1): Endoscopic photographs of the procedure; inflated balloon (black arrows).

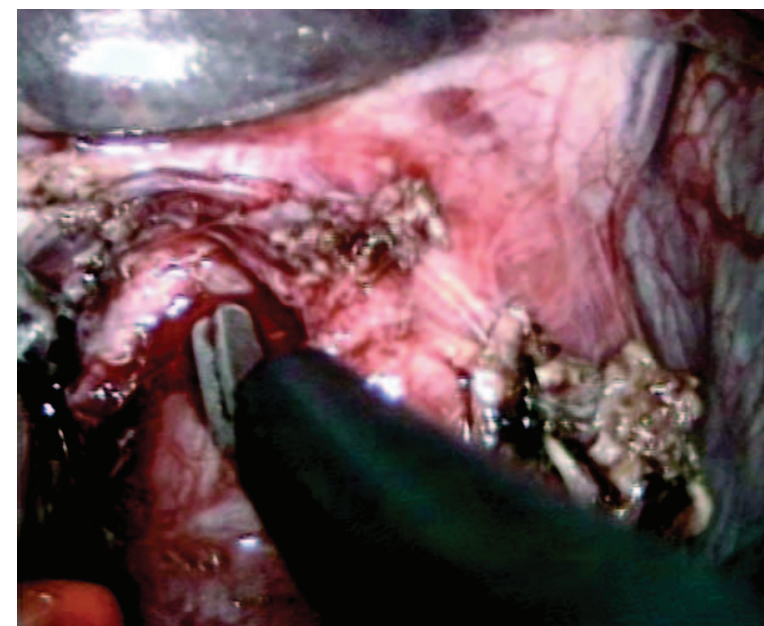

Figure (2): After minimal dissection of the anterior esophagus, a 6-8cm myotomy was performed. Scissors were used in the proximal part.

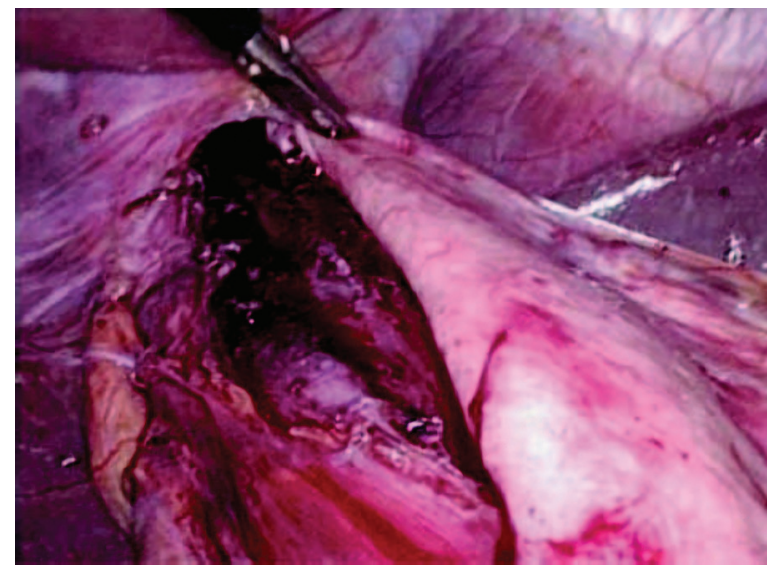

Figure (4): An anterior hemifundoplication (Dor) procedure was performed.

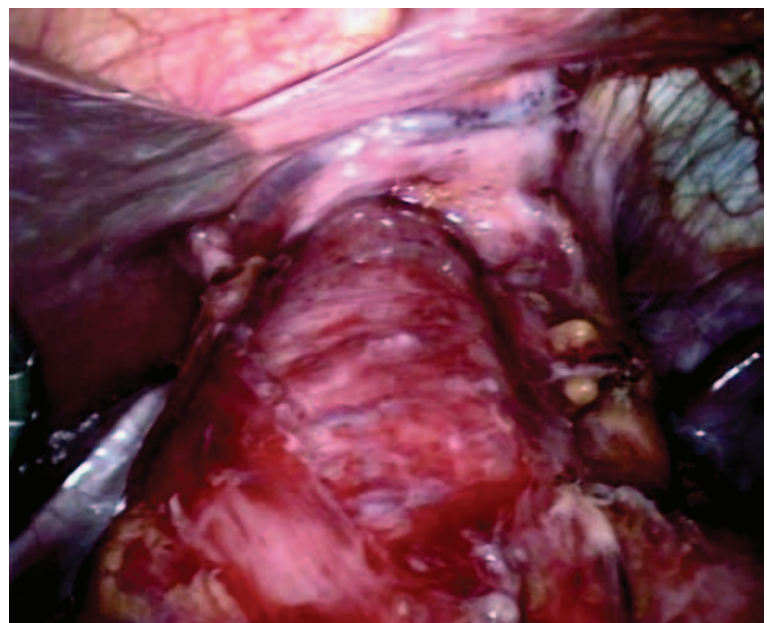

Figure (3): The myotomy was extended 1.5-2 cm downwards on the gastric wall using a hook.

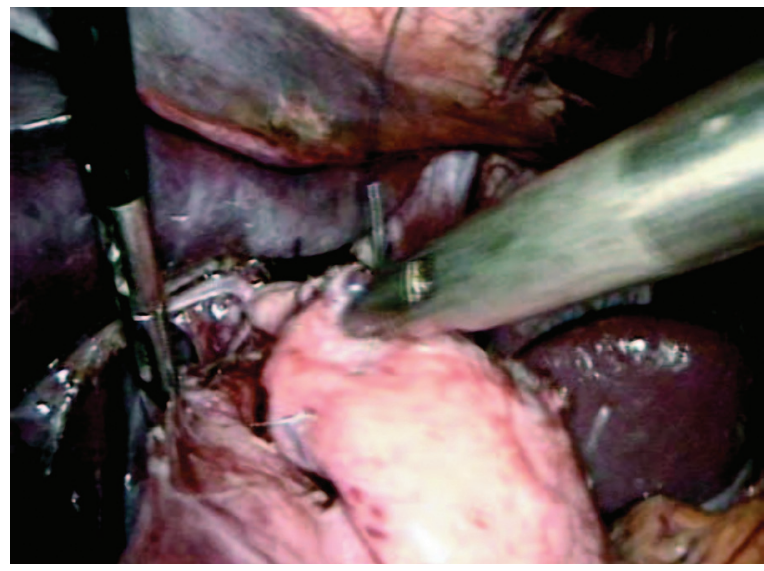

Figure (5): Three stitches were inserted on each side: the proximal stitch included the stomach, the edge of the myotomy and the diaphragm. 


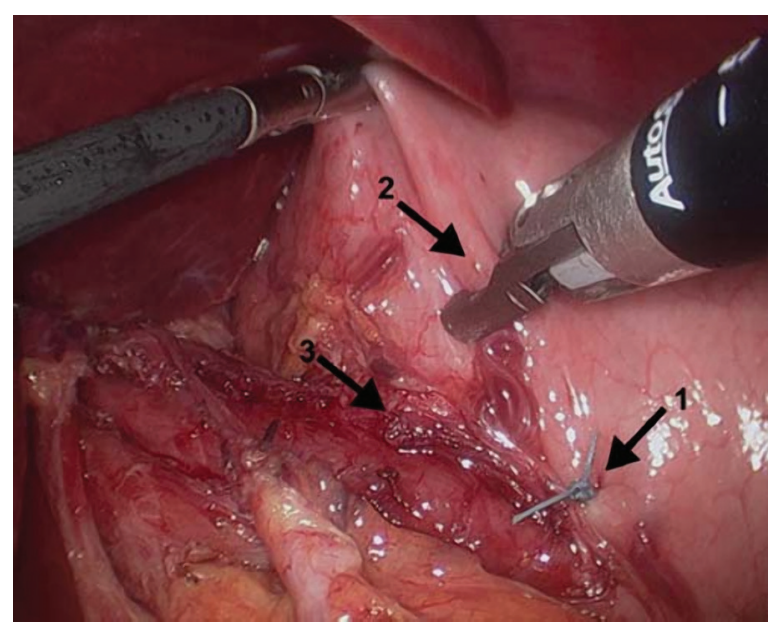

Figure (6): The creation of a Dor fundoplication. The first suture from the anterior portion of the fundus to the left edge of the myotomy (arrow 1). The second suture anchored the fundoplication and part of the myotomy in the abdomen by apposing the fundus (arrow 2) to the left crus (not shown) and then to left edge of the myotomy (arrow 3).

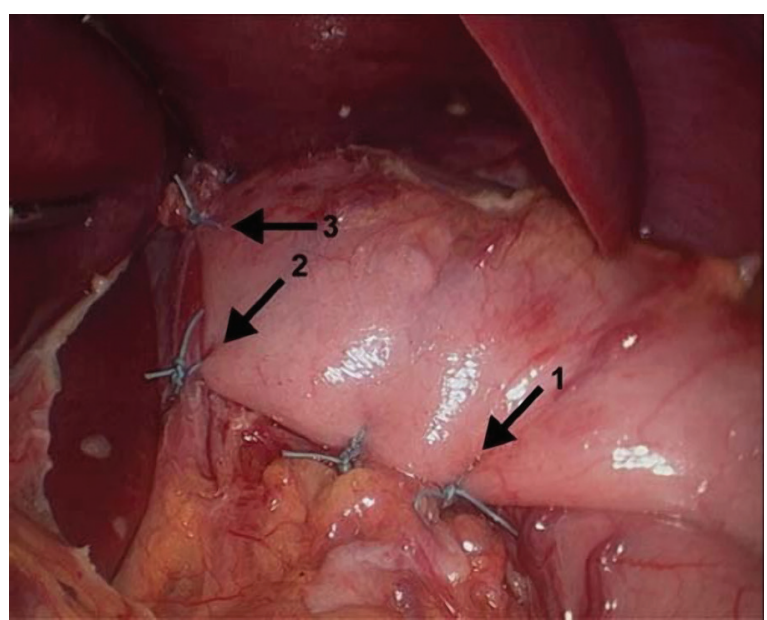

Figure (7): The completed Dor fundoplication. Arrows 1 and 2 show the suture line that anchored the fundoplication to the right edge of the myotomy. Arrow 2 incorporates the fundus, the right crus to the right edge of the myotomy. Arrow 3 points the suture that secured the fundoplication to the diaphragm.

\section{Table (1): Valiukenas Achalasia Severity Scoring:}

\begin{tabular}{|l|l|l|l|l|}
\hline \multirow{2}{*}{\multicolumn{1}{|c|}{ Symptoms }} & \multicolumn{4}{c|}{ Score } \\
\cline { 2 - 5 } & \multicolumn{2}{|c|}{$\mathbf{0}$} & \multicolumn{1}{c|}{$\mathbf{2}$} & \multicolumn{1}{c|}{$\mathbf{3}$} \\
\hline Dysphagia to solids & No & Weekly & Daily & Each meal \\
\hline Dysphagia to liquids & No & Weekly & Daily & Each meal \\
\hline Active regurgitation & No & Weekly & Daily & Each meal \\
\hline Passive regurgitation & No & Monthly & Weekly & Daily \\
\hline Chest pain & No & Monthly & Weekly & Daily \\
\hline
\end{tabular}

N.B: $\quad 1-5=$ mild symptoms $\quad 6-9=$ moderate symptoms

10 or more $=$ severe symptoms

Table (2): Comparison between symptom scoring in dilation and surgery group before the procedure:

\begin{tabular}{|l|l|l|l|l|}
\hline \multicolumn{2}{|c|}{ Dilation } & \multicolumn{2}{c|}{ Pre-procedure } \\
\cline { 3 - 4 } \multicolumn{2}{|c|}{} & \multicolumn{1}{|c|}{ Surgery } & \multicolumn{1}{c|}{ P-value } & \\
\hline \multirow{3}{*}{$\begin{array}{l}\text { Symptom } \\
\text { severity }\end{array}$} & No & $0(0 \%)$ & $0(0 \%)$ & \multirow{3}{*}{$>0.05$} \\
\cline { 2 - 4 } & Mild & $0(0 \%)$ & $0(0 \%)$ & \\
\cline { 2 - 5 } & Moderate & $12(80 \%)$ & $9(60 \%)$ & $6(40 \%)$ \\
\cline { 2 - 4 } & Severe & $3(20 \%)$ & \multicolumn{2}{|c}{} \\
\hline
\end{tabular}

To obtain an acceptable therapeutic effect, dilatation to a diameter of at least $3 \mathrm{~cm}$ was performed, and the procedure lowered the resting LES pressure to $10 \mathrm{~mm} \mathrm{Hg}$. The best results were obtained by using incrementally larger balloon sizes during successive 
Table (3): Comparison between symptom scoring in dilation and surgery group immediately after the procedure when starting oral intake:

\begin{tabular}{|c|c|c|c|c|}
\hline \multirow{2}{*}{\multicolumn{2}{|c|}{ Dilation }} & \multicolumn{3}{|c|}{ Immediately after starting oral intake } \\
\hline & & Surgery & P-value & \\
\hline \multirow{4}{*}{$\begin{array}{l}\text { Symptom } \\
\text { severity }\end{array}$} & No & $4(27 \%)$ & $6(40 \%)$ & \multirow{4}{*}{$<0.001$} \\
\hline & Mild & $8(53 \%)$ & $9(60 \%)$ & \\
\hline & Moderate & $3(20 \%)$ & $0(0 \%)$ & \\
\hline & Severe & $0(0 \%)$ & $0(0 \%)$ & \\
\hline
\end{tabular}

Table (4): Comparison between symptom scoring in dilation and surgery group after one month from the procedure:

\begin{tabular}{|c|c|c|c|c|}
\hline \multirow{2}{*}{\multicolumn{2}{|c|}{ Dilation }} & \multicolumn{3}{|c|}{ After one month } \\
\hline & & Surgery & P-value & \\
\hline \multirow{4}{*}{$\begin{array}{l}\text { Symptom } \\
\text { severity }\end{array}$} & No & $5(33 \%)$ & $12(80 \%)$ & \multirow{4}{*}{$<0.001$} \\
\hline & Mild & $9(60 \%)$ & $3(20 \%)$ & \\
\hline & Moderate & $1(7 \%)$ & $0(0 \%)$ & \\
\hline & Severe & $0(0 \%)$ & $0(0 \%)$ & \\
\hline
\end{tabular}

Table (5): Comparison between symptom scoring in dilation and surgery group after 6 months from the procedure:

\begin{tabular}{|c|c|c|c|c|}
\hline \multirow{2}{*}{\multicolumn{2}{|c|}{ Dilation }} & \multicolumn{3}{|c|}{ After 6 months } \\
\hline & & \multirow{2}{*}{\begin{tabular}{|l|} 
Surgery \\
$3(20 \%)$
\end{tabular}} & \begin{tabular}{|l|} 
P-value \\
\end{tabular} & \multirow{5}{*}{$<0.001$} \\
\hline \multirow{4}{*}{$\begin{array}{l}\text { Symptom } \\
\text { severity }\end{array}$} & No & & $13(87 \%)$ & \\
\hline & Mild & $9(60 \%)$ & $2(13 \%)$ & \\
\hline & Moderate & $3(20 \%)$ & $0(0 \%)$ & \\
\hline & \begin{tabular}{|l|} 
Severe \\
\end{tabular} & $0(0 \%)$ & $0(0 \%)$ & \\
\hline
\end{tabular}

Table (6): Comparison between symptom scoring in dilation and surgery group after 12 months from the procedure:

\begin{tabular}{|c|c|c|c|c|}
\hline \multirow{2}{*}{\multicolumn{2}{|c|}{ Dilation }} & \multicolumn{3}{|c|}{ After 12 months } \\
\hline & & Surgery & P-value & \\
\hline \multirow{4}{*}{$\begin{array}{l}\text { Symptom } \\
\text { severity }\end{array}$} & No & $0(0 \%)$ & $14(93 \%)$ & \multirow{4}{*}{$<0.001$} \\
\hline & Mild & $9(60 \%)$ & $1(7 \%)$ & \\
\hline & Moderate & $3(20 \%)$ & $0(0 \%)$ & \\
\hline & Severe & $3(20 \%)$ & $0(0 \%)$ & \\
\hline
\end{tabular}

Table (7): Comparison between the manometric findings (basal LES pressure) in dilation and surgery group before the procedure:

\begin{tabular}{|l|l|l|l|l|}
\hline \multicolumn{2}{|c|}{ Dilation } & \multicolumn{3}{c|}{ Pefore the procedure } \\
\cline { 3 - 4 } \multicolumn{2}{|c|}{} & \multicolumn{1}{|c|}{ Surgery } & \multicolumn{1}{c|}{ P-value } & \\
\hline \multirow{2}{*}{$\begin{array}{l}\text { Basal LES } \\
\text { pressure in } \\
\text { mmHg }\end{array}$} & $>45$ & $12(80 \%)$ & $13(87 \%)$ & \multirow{3}{*}{$>0.05$} \\
\cline { 2 - 4 } & $30-45$ & $3(20 \%)$ & $2(13 \%)$ & \\
\cline { 2 - 5 } & $<30$ & $0(0 \%)$ & $0(0 \%)$ & \\
\hline
\end{tabular}


Table (8): Comparison between the endoscopic findings in dilation and surgery group before the procedure:

\begin{tabular}{|c|c|c|c|c|}
\hline \multirow{2}{*}{\multicolumn{2}{|c|}{ Dilation }} & \multicolumn{3}{|c|}{ Before the procedure } \\
\hline & & Surgery & P-value & \\
\hline \multirow{4}{*}{$\begin{array}{l}\text { Endoscopic } \\
\text { findings }\end{array}$} & Spastic cardia \& dilated esophagus & $15(100 \%)$ & $15(100 \%)$ & \multirow{4}{*}{$>0.05$} \\
\hline & Dilated esophagus & $0(0 \%)$ & $0(0 \%)$ & \\
\hline & GERD & $0(0 \%)$ & $0(0 \%)$ & \\
\hline & No abnormalities & $0(0 \%)$ & $0(0 \%)$ & \\
\hline
\end{tabular}

Table (9): Comparison between the endoscopic findings in dilation and surgery group after one month from the procedure:

\begin{tabular}{|c|c|c|c|c|}
\hline \multirow{2}{*}{\multicolumn{2}{|c|}{ Dilation }} & \multicolumn{3}{|c|}{ After one month } \\
\hline & & Surgery & P-value & \\
\hline \multirow{4}{*}{$\begin{array}{l}\text { Endoscopic } \\
\text { findings }\end{array}$} & Spastic cardia \& dilated esophagus & $2(13 \%)$ & $0(0 \%)$ & \multirow{4}{*}{$<0.001$} \\
\hline & Dilated esophagus & $5(34 \%)$ & $2(13 \%)$ & \\
\hline & GERD & $2(13 \%)$ & $1(7 \%)$ & \\
\hline & No abnormalities & $6(40 \%)$ & $12(80 \%)$ & \\
\hline
\end{tabular}

Table (10): Comparison between the endoscopic findings in dilation and surgery group after 6 months from the procedure:

\begin{tabular}{|l|l|l|l|l|}
\hline \multicolumn{2}{|c|}{ Dilation } & \multicolumn{3}{c|}{ After 6 months } \\
\cline { 3 - 4 } \multicolumn{2}{|c|}{} & Surgery & \multicolumn{1}{|c|}{ P-value } & \\
\hline \multirow{4}{*}{$\begin{array}{l}\text { Endoscopic } \\
\text { findings }\end{array}$} & Spastic cardia \& dilated esophagus & $3(20 \%)$ & $0(0 \%)$ & \\
\cline { 2 - 4 } & Dilated esophagus & $1(7 \%)$ & $1(7 \%)$ & \multirow{2}{*}{0.001} \\
\cline { 2 - 4 } & GERD & $2(13 \%)$ & $0(0 \%)$ & \\
\cline { 2 - 4 } & No abnormalities & $9(60 \%)$ & $14(93 \%)$ & \\
\hline
\end{tabular}

Table (11): Comparison between the endoscopic findings in dilation and surgery group after 12 months from the procedure:

\begin{tabular}{|l|l|l|l|l|}
\hline \multicolumn{2}{|c|}{ Dilation } & \multicolumn{3}{c|}{ After 12 months } \\
\cline { 3 - 4 } \multicolumn{2}{|c|}{} & Surgery & \multicolumn{1}{|c|}{ P-value } & \\
\hline \multirow{4}{*}{$\begin{array}{l}\text { Endoscopic } \\
\text { findings }\end{array}$} & Spastic cardia \& dilated esophagus & $6(40 \%)$ & $0(0 \%)$ & \\
\cline { 2 - 4 } & Dilated esophagus & $0(0 \%)$ & $0(0 \%)$ & \multirow{2}{*}{$<0.001$} \\
\cline { 2 - 4 } & GERD & $1(7 \%)$ & $0(0 \%)$ & \\
\cline { 2 - 4 } & No abnormalities & $8(53 \%)$ & $15(100 \%)$ & \\
\hline
\end{tabular}

Table (12): Comparison between the two groups as regard the mean hospital stay (days):

\begin{tabular}{|l|l|l|l|}
\hline & Dilatation & Surgery & $\mathrm{P}$ \\
\hline 1 day & $12(80 \%)$ & $0(0 \%)$ & \multirow{3}{*}{$<0.001$} \\
\cline { 1 - 3 } 2 days & $1(7 \%)$ & $13(87 \%)$ & \\
\hline$>2$ days & $2(13 \%)$ & $2(13 \%)$ & \\
\hline
\end{tabular}


dilatations.

Patients who responded to dilatation were treated successfully with a second attempt, but patients who did not respond to a first dilatation were likely to fail additional dilatations.

The dilatation procedure was performed on an outpatient basis but the patient was observed for a minimum of 6 hours and prior to permission of oral feeding gastrographin swallow was performed in all cases of dilatation to rule out and diagnose early esophageal perforation.

\section{B- Surgery:}

Group (B): 15 patients who underwent laparoscopic Heller's myotomy combined with Dor fundoplication.

The operation was performed under general anesthesia. The patient was placed on the operating room table in supine position with legs abducted on flat padded leg boards to minimize the risk of lower extremity neurovascular injury. The right arm was tucked against the patient's side and the left arm remained on an arm board. The patient was well secured, as a steep reverse Trendelenburg was needed to displace the intra-abdominal organs from the subdiaphragmatic area and bring the surgical site closer to the surgeon. The surgeon stood between the abducted legs allowing easy access to the upper abdomen.

A urinary catheter and orogastric tubes were placed. Sequential pneumatic compression boots were placed. A video monitor was placed at the 12 o'clock position at the patient's head. The first assistant's monitor and all the remaining laparoscopic instrumentation were on a cart located in the 10 o'clock position. Pneumoperitoneum was established with the Veress needle through an umbilical puncture using carbon dioxide to achieve an intraabdominal pressure of $15-\mathrm{mm}$ $\mathrm{Hg}$. The first 10-mm trocar, for the telescope, was placed through the left rectus sheath medial to the epigastric vessels $15-\mathrm{cm}$ from the xiphoid. The remaining four trocars were inserted under direct vision. A liver retractor was passed through the right subcostal trocar and elevated the left liver lobe to expose the hiatus. The assistant retracted the epiphrenic fat pad caudally with atraumatic grasper through the $5 \mathrm{~mm}$ port in the left flank.

We followed a standardized technique where the esophageal hiatus was dissected exposing the lower esophagus anteriorly and upper part of diaphragmatic crura, establishing at least $2 \mathrm{~cm}$ of intra-abdominal esophagus and $6 \mathrm{~cm}$ of distal esophagus anteriorly for subsequent myotomy. The anterior vagus nerve was identified and left against the esophagus.

Any epiphrenic fat pad was resected and the myotomy completed by dividing the longitudinal and circular muscle fibers of the esophagus using ultrasonic dissector.

The myotomy was done at least $6 \mathrm{~cm}$ of distal esophagus and $1.5-2 \mathrm{~cm}$ onto the gastric side. The extent and completeness of the myotomy in addition to the integrity of the esophageal mucosa was checked by performing peroperative esophagoscopy to localize the squamocolumnar junction, to assure a widely patent esophagogastric junction, and distend the distal esophagus with air to visualize a bulging mucosa without remaining muscular bands. The mucosal surface was then submerged underwater, looking for bubbles that would suggest a mucosal perforation. An antireflux procedure was performed after completing the myotomy. Our preferred antireflux procedure to accompany Heller's myotomy was Dor fundoplication (anterior fundic wrap). The anterior fundic wall was sutured first to the left then to the right muscle edges of the myotomy with 3 interrupted sutures (vicryl 3/0). The proximal sutures included also the crura making the myotomy borders opened preventing their approximation.

Patient follow up:

All patients were followed up for 12 months after both procedures where clinical evaluation, contrast study, endoscopic examination, +/- esophageal manometry were performed for each of them.

Statistical methods:

Data were collected, tabulated, coded then 
analyzed using SPSS computer software version 12.0. A difference with "P" value < 0.05 was considered statistically significant otherwise it was insignificant.

\section{Results:}

Thirty patients with primary achalasia were randomized for either pneumatic balloon dilatation; Group A (15 patients) or laparoscopic Heller cardiomyotomy with Dor hemifundoplication; Group B (15 patients) in Ain Shams University Hospitals between June 2012 and October 2014.

\section{Patient demographics:}

Sex: In group A, there were 7 males (47\%) and 8 females (53\%), While group B, there were 6 males $(40 \%)$ and 9 females $(60 \%)$.

Age: In group A, the mean age was 41.6 year (22-63 years), while group B was 38.72 years (21-64 years) (P-value: $>0.05)$.

Analysis of the patient symptoms before and after the treatment procedures:

Comparison between the two groups was done. This was done before the procedure, immediately after the procedure, one month, 6 months and 12 months after the procedure as shown in Tables (2-6).

Results of the manometric assessment before and after the procedure:

A- Before the procedure, it was as follows:

B- After the procedure:

Manometric assessment was done only in 6 patients of the dilatation group who were presented with recurrence of symptoms during 12 months of follow up, four of these patients had basal LES pressure 30-45 and 2 patients had pressure $>45$. No patient in the group B needed to repeat the manometry postoperatively.

Endoscopic results before and after the procedure:

Comparison between the two groups as regard endoscopic findings was done before the procedure, one month, 6 months, and 12 months after the procedure as shown in Tables (8-11).

The procedure results:

Mean procedure duration (minutes):
Group A: 46.6 (40-60 min), Group B: 99 (80$120 \mathrm{~min})(\mathrm{P}$-value $<0.001)$

Mean hospital stay (days): Group A: 1.1, Group B: 2.1 (P-value < 0.001)

Intra-procedure complications:

As regard the intraoperative complications which had occurred in patients of group (A), only $1(7 \%)$ patient had mucosal tear who received conservative treatment and another 1 (7\%) patient had mucosal perforation which was diagnosed immediately and esophageal stent was inserted for 2 weeks.

While in group (B) there was $1(7 \%)$ patients with mucsal perforation which was identified and stitched laparoscopically by vicryl $2 / 0$.

Postoperative complications:

\section{Reflux symptoms:}

As regard the appearance or increase of the symptoms of reflux in group (A) patients, after balloon dilation, this was obvious in 2 $(13 \%)$ patients at the $1^{\text {st }}$ follow up visit after 1 month, $2(13 \%)$ patients at the $2^{\text {nd }}$ follow up visit after 6 months and one patient (7\%) at the $3^{\text {rd }}$ follow up visit after 12 months and these symptoms were confirmed by endoscopy, all the patients were treated conservatively.

While in group (B) patients, these symptoms appeared in one patient $(7 \%)$ at the $1^{\text {st }}$ follow up visit after 1 month. No patient had reflux symptoms at the follow up visit after 6 months and after 12 months.

Recurrence of achalasia symptoms:

In group (A) 6 (40\%) patients, complained of recurrence of symptoms and needed further dilatation during the 12 months of follow up. While in group B no patient needed laparoscopic remyotomy during the 12 months of follow up.

\section{Discussion:}

In achalasia, the lower esophageal sphincter is hypertonic producing resting pressures above normal and relaxing incompletely after swallowing. This produces a functional obstruction resulting in dilatation and elongation of the body of the esophagus 
with a rapid narrowing at the cardia. ${ }^{2}$

A reduction in the LES pressure can be obtained by disrupting the LES muscle fibers with different modalities of treatment including forceful endoscopic pneumatic dilatations, by cutting the muscle fibers (myotomy) or by offering botulinum toxin injection. ${ }^{6}$

Botulinum toxin has been abandoned as a first-line treatment because of its inferiority when studied during randomized clinical trial conditions. ${ }^{7}$ The therapies that have prevailed are forceful pneumatic dilatation and surgical myotomy with or without an anti-reflux repair. ${ }^{2}$

Traditionally, most newly diagnosed achalasia patients been offered a series of pneumatic dilatations, followed by surgical intervention if the dilatation failed. With the introduction of laparoscopic cardiomyotomy, changes in the initial management of the disease have been introduced. It is of utmost importance that highest grade of evidence be offered regarding which strategy i.e., endoscopy-based repetitive pneumatic dilatation or direct operation, exposing the patient to the lowest risk of failure. ${ }^{1}$

This study reports the short-term results of the randomized controlled clinical trial comparing the therapeutic outcome of laparoscopic cardiomyotomy with pneumatic dilatation in newly diagnosed idiopathic achalasia. We used the cumulative occurrence of clinical improvement as a primary outcome variable, which represents an approach to outcome assessment in achalasia.

During the 12 months of follow-up, we noted significantly more treatment failures in the dilatation strategy compared to the laparoscopic myotomy to which was added an anterior partial fundoplication to prevent reflux. In fact no failure was noted in the latter group, compared to 6 among those belonged to balloon dilatation.

Our results in idiopathic achalasia harmonize well with those reported some years ago by Csendes and colleagues 8 , when they randomized corresponding group of patients, also suffer from Chagas disease, to either an laparoscopic operation or forceful endoscopic dilatation In their landmark study a less rigid and updated dilatation protocol was followed, but despite this, a significant difference emerged in favor of the operation based strategy, with a progressive accumulation of failures over time among patients submitted to dilatation. It can, of course, be argued that the currently applied and predefined composite definition of treatment failures was too rigid and not clinically fully relevant. However an overt perforation in association with the dilatation represents an undisputable failure when it requires surgical correction.

Most observations, gained from singleinstitution retrospective analyses, favor the addition of the anti-reflux repair. The only randomized clinical trial presented so far clearly showed the rational for addition of a partial fundoplication (Dor procedure) to prevent reflux after the cardiomyotomy. Proponents of the Toupet procedure agree that it prevents re-approximation of the myotomy and may be better than an anterior fundoplication preventing postoperative reflux. On the other hand, advocates of the anterior repair agree that it is easy to perform, prevents re approximation of the myotomy, protects the anterior esophagus following myotomy and leaves the posterior anatomy of the gastroeosphageal junction intact. Future results of' prospective randomized studies should, however, settle this controversy. ${ }^{4}$

The response to the dilatation procedure was initially nearly the same as for surgery and all patients reported a drop in the symptom scores, but after 6 months myotomized patients already had a greater improvement in symptom score and soon afterward dysphagia and regurgitation recurred in nearly one third of the patients treated with dilatation. The likelihood of symptom recurrence in our dilatation group was $40 \%$ at 1 year, a figure coming between the results reported by Vaezi $(32 \%) .9$

Surgical myotomy in our study had an $93 \%$ chance of remaining symptom-free at 1 year, and this is much more consistent with other findings in the medical literature done by Bonavina et al. ${ }^{10}$ and Hunter et al. ${ }^{11}$ 


\section{Conclusion:}

Laparoscopic cardiomyotomy was found to be superior to an endoscopic balloon dilatation strategy in the treatment of achalasia when studied during the first 12 month after treatment with special care must be taken in the future studies to laparoscopic myotomy alone as it is thought to be the best way for the management of achalasia in the future.

\section{Reference:}

1- Kostic S, Kjellin A, Ruth M, Lönroth H, Johnsson E, Andersson M, et al: Pneumatic dilation or laparoscopic cardiomyotomy in the management of a newly diagnosed idiopathic achalasia. World J Surg 2007; 31(3): 470-478.

2- Abir F, Modlin I, Kidd M, Bell R: Surgical treatment of achalasia: Current status and controversies. Dig surg 2004; 21(3): 165-176.

3- Wang L, Li Y: Recurrent achalasia treated with Heller myotomy: A review of the literature. World J Gasteroenterol 2008; 14(46): 7122-7126.

4- Richards WO, Torquati A, Holzman MD, Khaitan L, Byrne D, Lutfi R, et al: Heller Myotomy Vs Heller Myotomy With Dor Fundoplication For Achalasia. A prospective randomized double blind clinical trial. Ann
Surg 2004; 240(3): 405-415.

5- Valiukenas V, Adomaviciute J, Lipnickas V, Brimas G, and Strupas K: Laparoscopic Surgery or Pneumatic Dilatation for Oesophageal Achalasia. Acta Medica Lituanica 2007; 14(4): 252-256.

6- West RL, Hirsch DP, Bartlelsman JFWM, De Borst, Ferwerda G, Tytgat GN, et al: Long term results of pneumatic dilataion in achalasia followed up for more than five years. Am J Gastroentrol 2002; 97(6):1346-1352.

7- Zaninotto G, Portale G, Parenti A, Lanza C, Costantini M, Molena D, et al: Role of acid and bile reflux in development of specialized intestinal metaplasia in distal oesophagus. Dig Liver Dis 2002; 34(4): 251-257.

8- Csendes A, Braghetto I, Burdiles P, Korn O, Csendes P, Henríquez A: Very late results of esophagomyotomy for patienrs with achalasia. Ann Surg 2006; 243(2): 196-203.

9- Vaezi MF and Richter JE: Current therapeies for achalasia: Comparison and efficacy. $J$ Clin Gastroenterol 1998; 27(1): 21-35.

10- Bonavina L, Incarbone $\mathrm{R}$, Reitano $\mathrm{M}$, Antoniazzi L, Peracchia A: Does previous endoscopic treatment affect the outcome of laparoscopic Heller myotomy? Ann Chir 2000; 125(1): 45-49.

11- Hunter JG, Trus TL, Branum GD, Waring JP: Laparoscopic Heller Myotomy and Dor Fundoplication for Achalasia. Ann Surg 1997; 225(6): 655-664. 